\title{
$\stackrel{\infty}{\circ}$ OPTIMIZACIJA OBLIKA KOMANDNIH POVRŠINA RAKETE
}

Pukovnik mr Zoran Rajić, dipl. inž.

Uprava za odbrambene tehnologije MO

Rezime:

U radu je prikazan jedan od rezultata istraživanja u oblasti optimizacije procesa preliminarnog aerodinamičkog proračuna raketa. Opisan je proces dobijanja optimalnog oblika komandnih površina rakete, u okviru preliminarnog aerodinamičkog proračuna raketa.

Posebna pažnja posvećena je definisanju funkcije cilja na nov način, tako da svako odstupanje od njene maksimalne vrednosti nedvosmisleno i očigledno ukazuje na to koja se od zadatih ciljnih veličina i u kojoj meri ne dostiže, odnosno da izabrani oblik rakete ne obezbeđuje u potpunosti sve unapred postavljene ciljeve.

Ključne reči: raketa, preliminarni aerodinamički proračun, aerodinamički koeficijent, optimizacija, funkcija cilja.

\section{OPTIMIZATION OF THE ROCKET COMMANDING SURFACES}

\section{Summary:}

The paper presents one of the author's research results in the field of the preliminary aerodynamic optimization process.

The optimal shape of commanding surfaces is obtained and described within the preliminary rocket aerodynamic estimation.

Special attention is paid to defining the target function in a new manner, such that every deviation from the target function maximum value clearly and obviously points out which of target values is not attained and to what extent, i.e. that the chosen rocket shape does not completely provide for all previously set goals.

Key words: blowdown wind tunnel, transient loads, wind tunnel models, wind tunnel balances, Schlieren system.

\section{Uvod}

Qealizacija projekta podrazumeva realizaciju niza različitih aktivnosti,

Ročevši od istraživanja, projektovanja, proizvodnje funkcionalnog modela, prototipa, nulte serije, serijske proizvodnje, ispitivanja, kontrole kvaliteta, uvođenja u eksploataciju, do obezbeđenja u toku eksploatacije.

Projektovanje, kao jedna od aktivnosti u procesu realizacije projekta, obuhvata realizaciju čitavog niza podaktivnosti koje treba na skladan na- 
čin povezati radi postizanja vrhunskih performansi tehničkih sistema koji su predmet projektovanja.

Preliminarno aerodinamičko projektovanje, kao podaktivnost u fazi projektovanja, jeste iterativan proces koji počinje inicijalnim definisanjem oblika (geometrije), a završava se postizanjem unapred zadatih aerodinamičkih ciljeva, uz istovremeno zadovoljenje svih postavljenih ograničenja. Sa aspekta ekonomičnosti poželjno je da traje što kraće.

Predmet ovog rada je optimizacija procesa preliminarnog aerodinamičkog projektovanja usvojenog koncepta komandnih površina rakete (slika 1$)$.

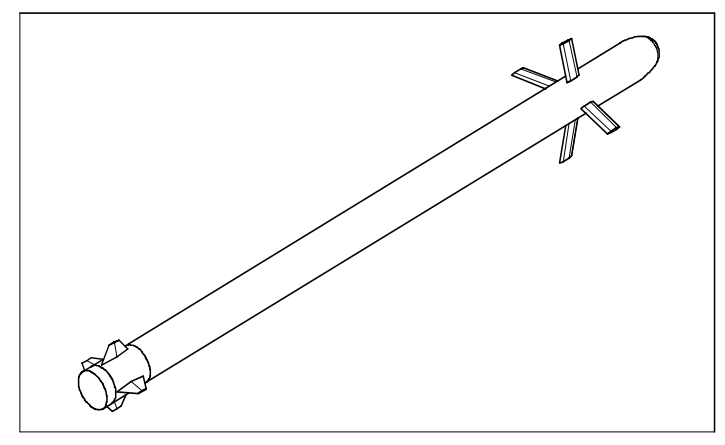

SI. 1 - Usvojeni koncept rakete

\section{Početno definisanje geometrije}

Početno definisanje geometrije komandnih površina rakete sledi odmah nakon usvajanja koncepta rakete i predstavlja ulaznu veličinu u proces aerodinamičkog proračuna.

Početna geometrija je, radi optimizacije, definisana tako što su za pojedine geometrijske veličine a priori usvojene dimenzije, a ostale veličine su tretirane kao promenljive (varijabilne).

$U$ slučaju komandnih površina rakete prva dilema jeste izbor najpogodnijeg aeroprofila, koji predstavlja kompromis između aerodinamičkih i konstrukcionih zahteva. U konkretnom slučaju, za izabranu konfiguraciju rakete i predviđene uslove leta $(0 \leq \mathrm{M} \leq 1,8)$ optimalni oblik aeroprofila komandnih površina prikazan je na slici 2.

Ovi aeroprofili obezbeđuju stru-

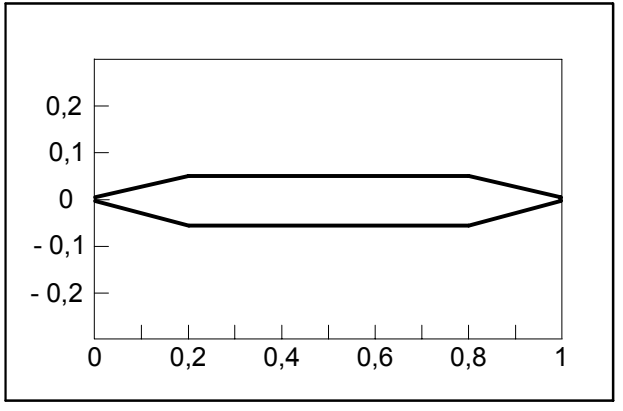

SI. 2 - Aeoprofil komandne površine janje kroz kose i ekspanzione udarne talase, čime smanjuju talasni otpor u nadzvučnom strujnom polju i daju manji doprinos ukupnom aerodinamičkom otporu rakete. Zbog smanjenja talasnog otpora i izravnavanja krive uzgona u transsoničnim uslovima leta izabrane su komandne povr- 
šine rakete sa pozitivnim uglom strele $(\theta)$. Vrednost ugla strele, kao i suženje komandne površine $\left(\frac{c_{t}}{c_{r}}\right)$, nije a priori određena, nego će biti razmatrana u okviru aerodinamičkog proračuna.

Radi optimizacije procesa preliminarnog aerodinamičkog proračuna rakete dužina tetive aeroprofila u korenu komandne površine određena je na osnovu iskustva, $\left(c_{r}\right)_{c}=30 \mathrm{~mm}$. Kako se radi o malim uzgonskim površinama, radi fabrikacije, ograničena je i maksimalna relativna debljina aeroprofila komandnih površina na $\left(\frac{t}{c_{r}}\right)_{\max }^{c}=0,1$, a radijus napadnih i izlaznih ivica komandnih površina je limitiran na $r_{l}=r_{t}=0,3 \mathrm{~mm}$. Radi zadovoljenja uslova stabilnosti rakete u zadatom dijapazonu brzina $(\mathrm{M} \leq 1,8)$, pomeranje centra pritiska na komandnoj površini biće ograničeno na $\left(\frac{x_{C P}}{c_{r}}\right)_{\Delta} \leq 0,25$.

Zbog smeštaja komandnih površina u trupu rakete u sklopljenom položaju polurazmah jedne komandne površine može maksimalno da iznosi $b=80 \mathrm{~mm}$.

Pregled unapred definisanih geometrijskih veličina (fiksnih) i geometrijskih veličina koje proračunom treba da se odrede kako bi se zadovoljili unapred postavljeni ciljevi prikazan je na slici 3.

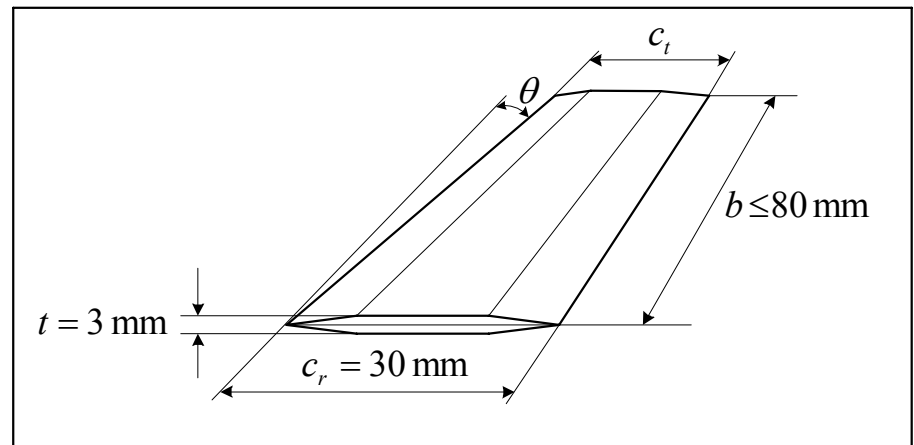

SI. 3 - Početne geometrijske veličine komandnih površina

\section{Aerodinamički proračun}

Aerodinamički proračun vrši se raspoloživim, pogodno izabranim kompjuterskim programima, radi dobijanja željenih izlaznih veličina zadovoljavajuće tačnosti. Izlazne veličine najčešće su: koeficijenti uzgona, ot- 
pora, momenata, pritiska, zatim raspored aerodinamičkog opterećenja po površini tela, relativno pomeranje centra pritiska, parametri strujanja u željenim tačkama strujnog polja, itd.

$\mathrm{Na}$ osnovu definisanih geometrijskih parametara komandnih površina, varijacijom promenljivih $\theta, b$ i $c_{t}$, biće izvršen njihov aerodinamički proračun upotrebom kompjuterskog programa WAC, razvijenog u Vojnotehničkom institutu.

Ulazni podaci u ovaj program su: geometrijske veličine tela, Mahov broj leta, broj napadnih uglova i korak za napadni ugao. Izlazni podaci iz programa WAC, značajni za ovaj rad, jesu: koeficijent normalne sile $\mathrm{C}_{\mathrm{N}} \mathrm{i}$ relativno pomeranje centra pritiska $\frac{x_{C P}}{c_{r}}$, u funkciji napadnog ugla. Izlazni podaci i njima odgovarajući ulazni podaci formiraju bazu podataka.

Zbog malih dimenzija komandnih površina i male relativne debljine aeroprofila, kao i ispunjenja uslova čvrstoće konstrukcije, vrednost dužine tetive na kraju komandnih površina $c_{t}$ limitirana je na $28 \mathrm{~mm}$. Kako se sa povećanjem strele komandnih površina smanjuje maksimalni koeficijent uzgona, a zbog potrebe da koeficijent uzgona bude dovoljno veliki zbog efikasnosti komandnih površina, ugao strele $(\theta)$ ograničen je na $13^{0}$. Ugao strele napadne ivice komandnih površina ograničen je i zbog izbegavanja mogućnosti preopterećenja konstrukcije krajeva komandnih površina, pošto se sa povećanjem strele povećava i opterećenje na krajevima (tabela 1).

Tabela 1

\begin{tabular}{|c|c|c|}
\hline Veličina & Fiksna & Promenljiva \\
\hline$\theta$ & & $0^{0}-13^{0}$ \\
\hline$b$ & & $0,040-0,080 \mathrm{~m}$ \\
$\lambda$ & & $0,002320-0,004640 \mathrm{~m}^{2}$ \\
\hline$c_{r}$ & $0,030 \mathrm{~m}$ & \\
\hline$c_{t}$ & & $0,028-0,030 \mathrm{~m}, 517$ \\
$c_{t} / c_{r}$ & & $0,9333-1,0$ \\
\hline$t$ & $0,003 \mathrm{~m}$ & \\
$t / c_{r}$ & 0,1 & \\
\hline
\end{tabular}

Grafička interpretacija rezultata proračuna u okolini optimalnog rešenja prikazana je na dijagramima 1 i 2 . Koeficijent normalne sile je $C N$, a $\Delta$ je relativno pomeranje centra pritiska $(x c p / c r)$ u dijapazonu brzina $0,5 \leq M \leq 1,8$. 

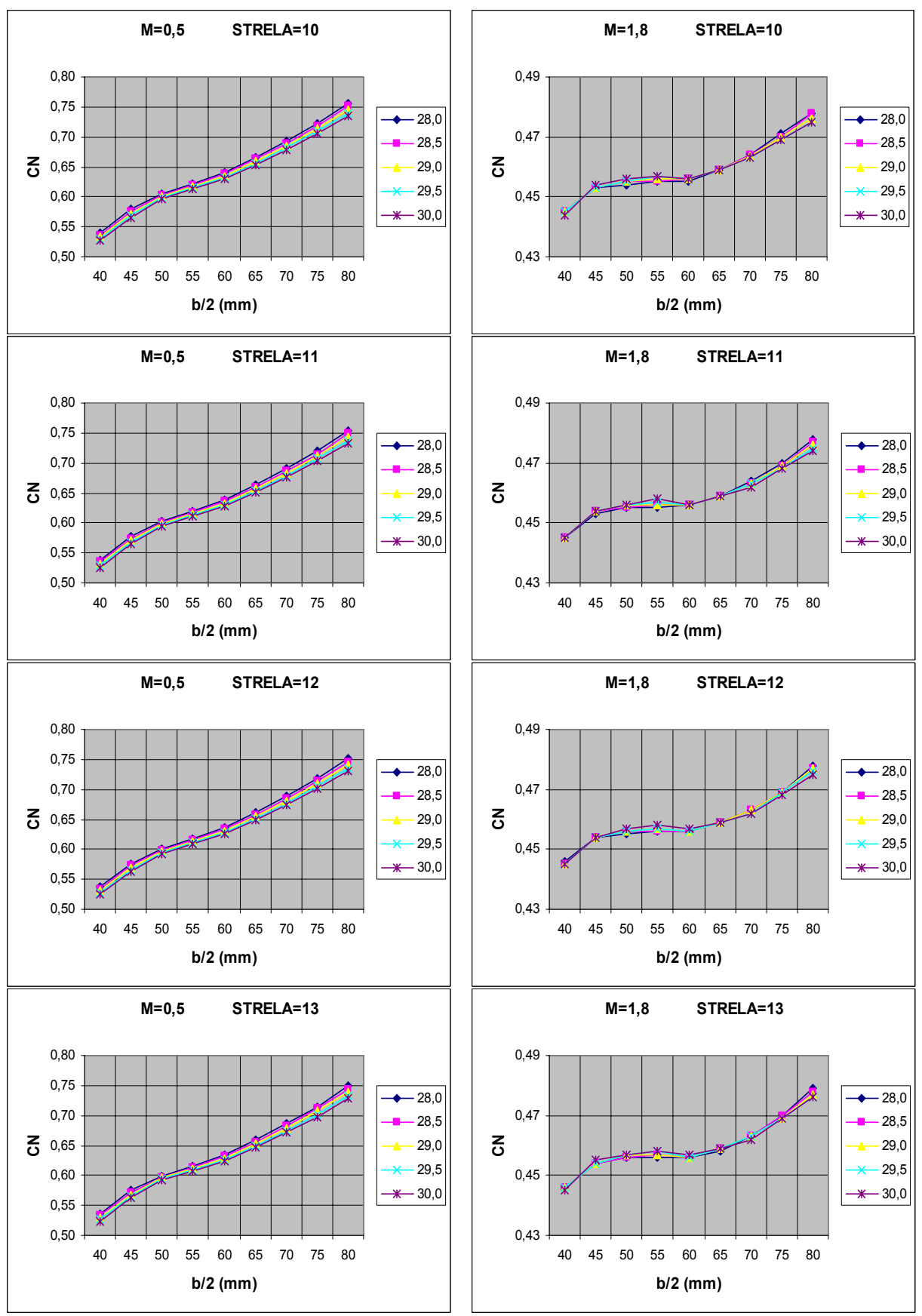

Dijagram 1 - Promena $\mathrm{C}_{\mathrm{N}}$ u funkciji b/2, M , $\theta$ i $\mathrm{C}_{\mathrm{t}}$ 

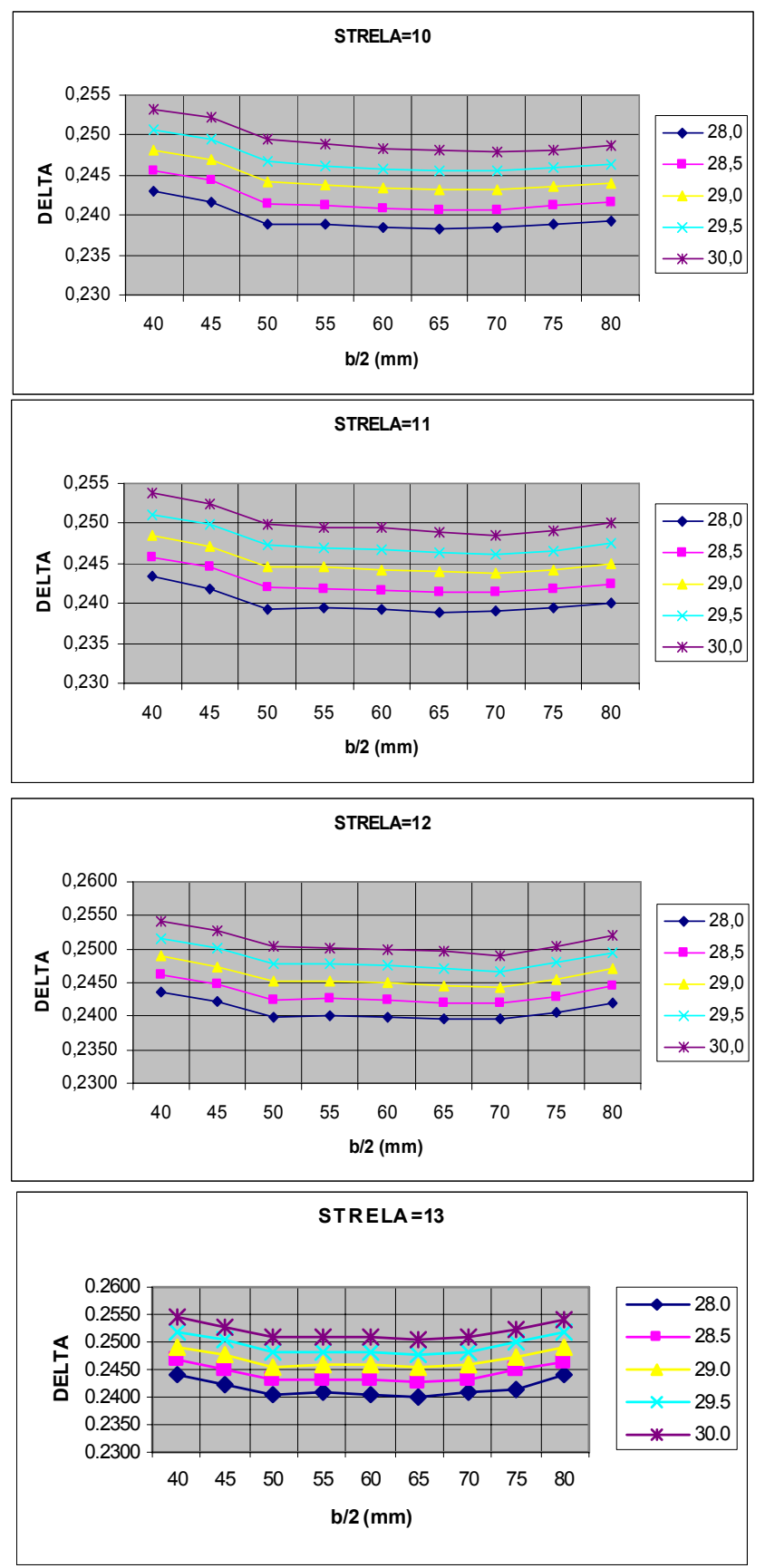

Dijagram 2 - Promena $\Delta \mathrm{u}$ funkciji b/2, $\theta \mathrm{i} \mathrm{c}_{\mathrm{t}}$ 


\section{Optimizacija oblika - definisanje funkcije cilja}

Sledeći korak je izbor optimalnog rešenja, tj. optimalnog oblika komandnih površina, koji zadovoljava funkciju cilja. Radi njegovog pojednostavljenja funkcija cilja je definisana na nov način, kao parabolična funkcija geometrijskih parametara, proračunom dobijenih adekvatnih aerodinamičkih veličina i pogodno izabranih koeficijenata. Vrednost funkcije cilja (f) izračunata je za nadzvučni režim leta $(M=1,8)$.

Funkcija cilja definisana je u sledećem obliku:

$$
f\left(M, C_{N}, \frac{b}{2}, \Delta\right)=f_{1}\left(C_{N}\right)+f_{2}\left(\frac{b}{2}\right)+f_{3}(\Delta)
$$

gde su $f_{1}, f_{2}$, i $f_{3}$ komponente funkcije cilja koje predstavljaju doprinos koeficijenta normalne sile $\left(C_{N}\right)$, polurazmaha $\left(\frac{b}{2}\right)$ i relativnog pomeranja centra pritiska $(\Delta)$ ukupnoj vrednosti funkcije cilja, respektivno:

$$
f=-\omega_{1} \tau_{C_{N}}\left(C_{N}{ }^{*}-C_{N}\right)^{2}-\omega_{2} \tau_{b}\left(\left(\frac{b}{2}\right)^{*}-\frac{b}{2}\right)^{2}-\omega_{3} \tau_{\Delta}\left(\Delta^{*}-\Delta\right)^{2}
$$

Maksimalna vrednost funkcije cilja odgovara optimalnom rešenju, odnosno optimalnom obliku komandne površine. Veličine označene zvezdicom $(*)$ jesu ciljne veličine, određene na osnovu eksperimentalnih i teorijskih saznanja:

$$
C_{N}{ }^{*}(M=1,8)=0,48,\left(\frac{b}{2}\right)^{*}=0,05 \mathrm{~m}, \Delta^{*}=\left(\frac{x_{C P}}{c_{r}}\right)^{*}=0,244
$$

Odstupanje $f_{1}, f_{2}$ i $f_{3}$ od maksimalne vrednosti $(0,00)$ ukazuje na stepen odstupanja $C_{N}, \frac{b}{2}, \Delta$ od ciljnih vrednosti $C_{N}{ }^{*},\left(\frac{b}{2}\right)^{*}, \Delta^{*}$, respektivno.

Proizvoljnim izborom težinskih koeficijenata $\omega_{1}=\omega_{2}=\omega_{3}=100$ obezbeđuje se željeni red veličina pojedinih komponenti funkcije cilja ( $f_{1}$, $f_{2}, f_{3}$ ), a samim tim i cele funkcije cilja. 
Izborom koeficijenata značajnosti $\tau_{C N}, \tau_{b}, \tau_{\Delta}$ definiše se značaj (uticaj) pojedinačnih komponenti funkcije cilja $\left(f_{1}, f_{2}, f_{3}\right)$ na ukupnu vrednost funkcije cilja $(f)$ i time svesno daje prioritet pojedinim promenljivim u dostizanju željenih vrednosti.

$S$ obzirom na to da je podjednako značajno da izabrana geometrija komandne površine rakete obezbedi relativno pomeranje centra pritiska manje od 0,25 (izabrano je ciljno pomeranje $\Delta^{*}=0,244$ ) i dostizanje ciljne vrednosti koeficijenta normalne sile $\left(C_{N}^{*}=0,48\right)$, a kako nije neophodno da polurazmah bude $\left(\frac{b}{2}\right)^{*}=50 \mathrm{~mm}$ (jedino je potrebno da bude manji ili jednak $80 \mathrm{~mm}$ ), definisane su sledeće vrednosti koeficijenata značajnosti:

$$
\tau_{\Delta}=1, \tau_{C N}=1, \tau_{b}=0,1
$$

Koristeći vrednosti (3), (4) i podatke iz baze podataka, upotrebom izraza (2), za zadata ograničenja, izračunate su vrednosti funkcije cilja, čija je grafička interpretacija prikazana na dijagramu 3.

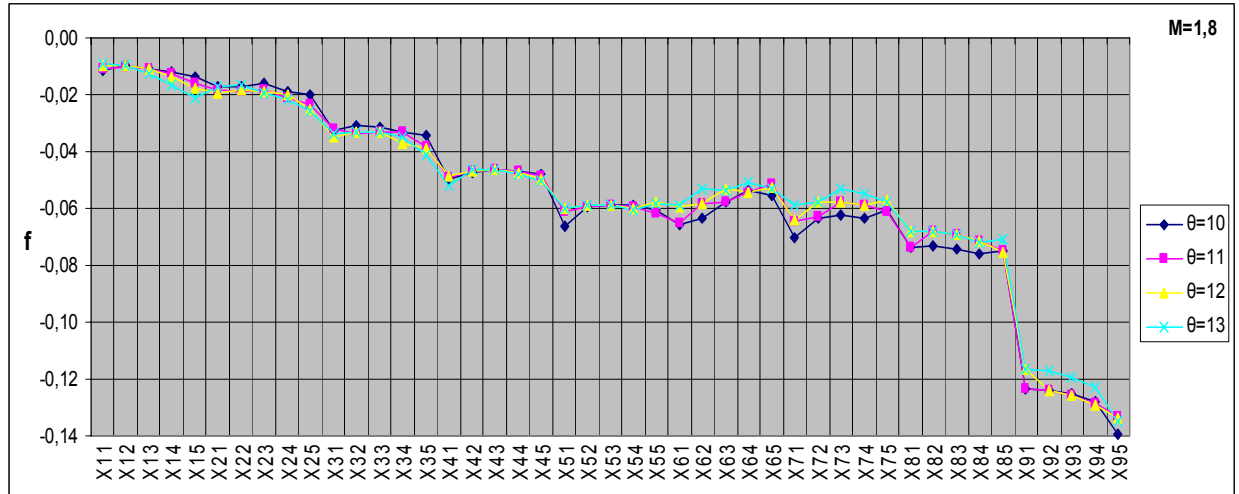

Dijagram 3 - Promena funkcije cilja u funkciji X i $\theta$

S obzirom na oblik funkcije, svrsishodno je analizirati funkciju cilja u okolini promenljive X12 (dijagram 4).

Za uvedena ograničenja $\frac{b}{2} \leq 80 \mathrm{~mm}$ i $c_{t} \geq 28 \mathrm{~mm}$, maksimalna vrednost funkcije cilja $\left({ }_{\max } f=-0,0091\right)$ odgovara promenljivoj $\mathrm{X}_{11}=\mathrm{X}_{\mathrm{OPT}}$, za koju je: 
$c_{r}=30 \mathrm{~mm}, c_{t}=28 \mathrm{~mm}, \frac{b}{2}=80 \mathrm{~mm}, \theta=13^{\circ}, \frac{t}{c_{r}}=0,1$

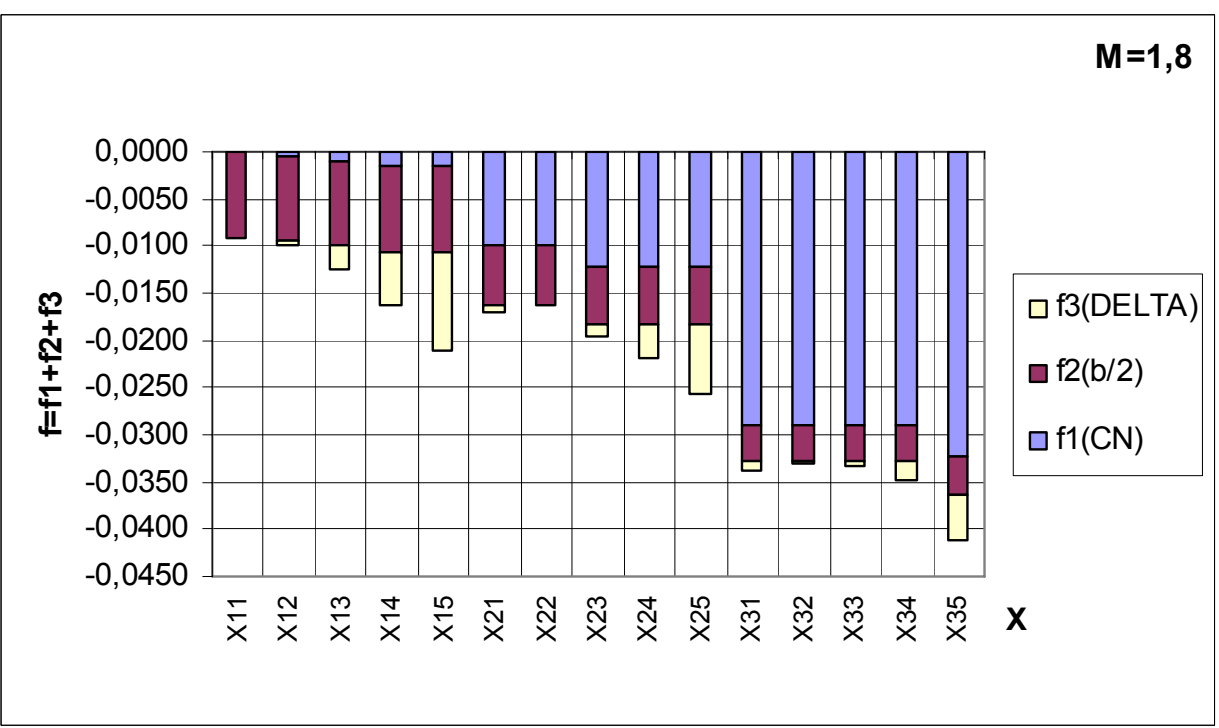

Dijagram 4 - Doprinos komponenata funkcije cilja njenoj ukupnoj vrednosti

Dobijeno rešenje obezbeđuje relativno pomeranje centra pritiska $\Delta=0,2439$ (željeno pomeranje je $\Delta^{*}=0,2440$ ) i koeficijent uzgona $C_{N}=0,479$ pri $M=1,8$, što je skoro jednako željenom $C_{N}{ }^{*}=0,48$ (tabela 2).

Tabela 2

\begin{tabular}{|c|c|c|c|c|}
\hline Ograničenja & Željene vrednosti & $\begin{array}{l}\text { Koeficijenti } \\
\text { značajnosti }\end{array}$ & $\begin{array}{l}\text { Optimalno } \\
\text { rešenje }\left(X_{11}\right)\end{array}$ & $\begin{array}{l}\text { Dobijene } \\
\text { vrednosti }\end{array}$ \\
\hline $\begin{array}{l}\frac{b}{2} \leq 80 \mathrm{~mm} \\
c_{t} \geq 28 \mathrm{~mm} \\
\theta \leq 13^{\circ} \\
\frac{t}{c_{r}}=0,1 \\
c_{r}=30 \mathrm{~mm} \\
\Delta \leq 0,25\end{array}$ & $\begin{array}{l}\left(\frac{b}{2}\right)^{*}=50 \mathrm{~mm} \\
C_{N}{ }^{*}=0,48 \\
\Delta^{*}=0,244\end{array}$ & $\begin{array}{l}\tau_{b}=0,1 \\
\tau_{C N}=1 \\
\tau_{\Delta}=1\end{array}$ & $\begin{array}{l}\frac{b}{2}=80 \mathrm{~mm} \\
c_{t}=28 \mathrm{~mm} \\
\theta=13^{\circ} \\
\frac{t}{c_{r}}=0,1 \\
c_{r}=30 \mathrm{~mm}\end{array}$ & $\begin{array}{l}C_{N}=0,479 \\
\Delta=0,2439\end{array}$ \\
\hline
\end{tabular}


Upravo zbog toga što nisu u potpunosti dostignute sve željene vrednosti, funkcija cilja nema svoju maksimalnu vrednost (0), nego nešto manju $(-0,0091)$.

Sa dijagrama 4 se vidi da najvećeg udela u odstupanju vrednosti funkcije cilja od svoje maksimalne vrednosti ima polurazmah $(b / 2)$, dok je uticaj relativnog pomeranja centra pritiska $(\Delta)$ i koeficijenta normalne sile $\left(C_{N}\right)$ skoro zanemarljiv. To je logičan rezultat $\mathrm{s}$ obzirom na to da je unapred definisan željeni polurazmah bio $\left(\frac{b}{2}\right)^{*}=0,05 \mathrm{~m}$, a dobijeno je optimalno rešenje $b / 2=0,08 \mathrm{~m}$. Ovoliko odstupanje od željenog rešenja nije greška, jer je značaj dostizanja $\left(\frac{b}{2}\right)^{*}$ bio samo $10 \%$ u odnosu na $C_{N}{ }^{*}$ i $\Delta^{*}(100 \%)$.

Radi analize funkcije cilja biće razmotreno još nekoliko slučajeva.

Da je, na primer, favorizovan značaj polurazmaha $\left(\frac{b}{2}\right)^{*}=0,05 \mathrm{~m}$ (100\%), zatim $C_{N}^{*}=0,48(50 \%)$ i $\Delta^{*}=0,244(10 \%)$, maksimalna vrednost funkcije cilja bila bi ${ }_{\text {max }} f\left(X_{73}\right)=-0,0053$, za $X_{73}=X_{O P T}$ (dijagram 5).

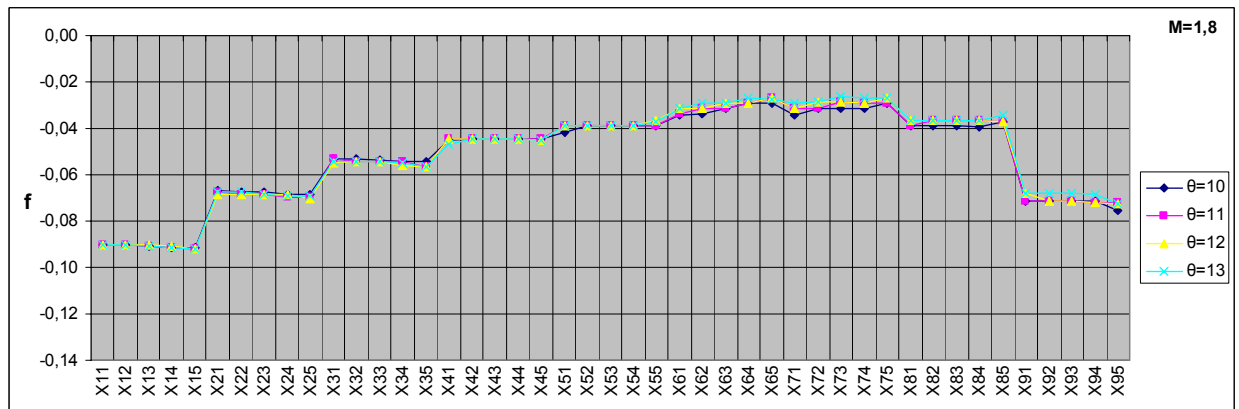

Dijagram 5 - Promena funkcije cilja u funkciji X i $\theta$

Dobijeno optimalno rešenje $\left(\frac{b}{2}=50 \mathrm{~mm}\right.$ i $\left.c_{t}=29 \mathrm{~mm}\right)$ i vrednosti za $C_{N}=0,457$ i $\Delta=0,2456$ logična su posledica definisanih koeficijenata značajnosti i željenih vrednosti. $S$ obzirom na to da je prioritet dat 
dostizanju željenog polurazmaha $\left(\tau_{b}=1\right)$, a da je od sekundarnog značaja bilo dostizanje željenog koeficijenta normalne sile $C_{N}\left(\tau_{\mathrm{CN}}=0,5\right) \mathrm{i}$ relativnog pomeranja centra pritiska $\Delta\left(\tau_{\Delta}=0,1\right)$, rezultat je očekivan (tabela 3).

Tabela 3

\begin{tabular}{|l|l|l|l|l|}
\hline \multicolumn{1}{|c|}{ Ograničenja } & \multicolumn{1}{|c|}{$\begin{array}{c}\text { Željene } \\
\text { vrednosti }\end{array}$} & $\begin{array}{l}\text { Koeficijenti } \\
\text { značajnosti }\end{array}$ & $\begin{array}{c}\text { Optimalno } \\
\text { rešenje }\left(\mathrm{X}_{73}\right)\end{array}$ & \multicolumn{1}{|c|}{$\begin{array}{c}\text { Dobijene } \\
\text { vrednosti }\end{array}$} \\
\hline$\frac{b}{2} \leq 80 \mathrm{~mm}$ & $\left(\frac{b}{2}\right)^{*}=50 \mathrm{~mm}$ & $\begin{array}{l}\tau_{b}=1 \\
\tau_{C N}=0,5\end{array}$ & $\frac{b}{2}=50 \mathrm{~mm}$ & $C_{N}=0,457$ \\
$c_{t} \geq 28 \mathrm{~mm}$ & $C_{N}{ }^{*}=0,48$ & $\tau_{\Delta}=0,1$ & $c_{t}=29 \mathrm{~mm}$ & $\Delta=0,2456$ \\
$\theta \leq 13^{\circ}$ & $\Delta^{*}=0,244$ & & $\theta \leq 13^{\circ}$ & \\
$\frac{t}{c_{r}}=0,1$ & & & $\frac{t}{c_{r}}=0,1$ & \\
$c_{r}=30 \mathrm{~mm}$ & & & $c_{r}=30 \mathrm{~mm}$ & \\
\hline
\end{tabular}

U slučaju da su sve željene vrednosti istog prioriteta i da su definisane kao u tabeli 4, funkcija cilja imala bi svoj maksimum ${ }_{\text {max }} f\left(X_{41}\right)=-0,0089$ (dijagram 6), a optimalno rešenje bilo bi $X_{41}=X_{O P T}$.

Tabela 4

\begin{tabular}{|c|c|c|c|c|}
\hline Ograničenja & $\begin{array}{l}\text { Željene } \\
\text { vrednosti }\end{array}$ & $\begin{array}{l}\text { Koeficijenti } \\
\text { značajnosti }\end{array}$ & $\begin{array}{l}\text { Optimalno } \\
\text { rešenje }\left(X_{41}\right)\end{array}$ & $\begin{array}{l}\text { Dobijene } \\
\text { vrednosti }\end{array}$ \\
\hline $\begin{array}{l}\frac{b}{2} \leq 80 \mathrm{~mm} \\
c_{t} \geq 28 \mathrm{~mm} \\
\theta \leq 13^{\circ} \\
\frac{t}{c_{r}}=0,1 \\
c_{r}=30 \mathrm{~mm}\end{array}$ & $\begin{array}{l}\left(\frac{b}{2}\right)^{*}=70 \mathrm{~mm} \\
C_{N}{ }^{*}=0,45 \\
\Delta^{*}=0,24\end{array}$ & $\begin{array}{l}\tau_{b}=1 \\
\tau_{C N}=1 \\
\tau_{\Delta}=1\end{array}$ & $\begin{array}{l}\frac{b}{2}=65 \mathrm{~mm} \\
c_{t}=28 \mathrm{~mm} \\
\theta \leq 13^{\circ} \\
\frac{t}{c_{r}}=0,1 \\
c_{r}=30 \mathrm{~mm}\end{array}$ & $\begin{array}{l}C_{N}=0,458 \\
\Delta=0,2401\end{array}$ \\
\hline
\end{tabular}




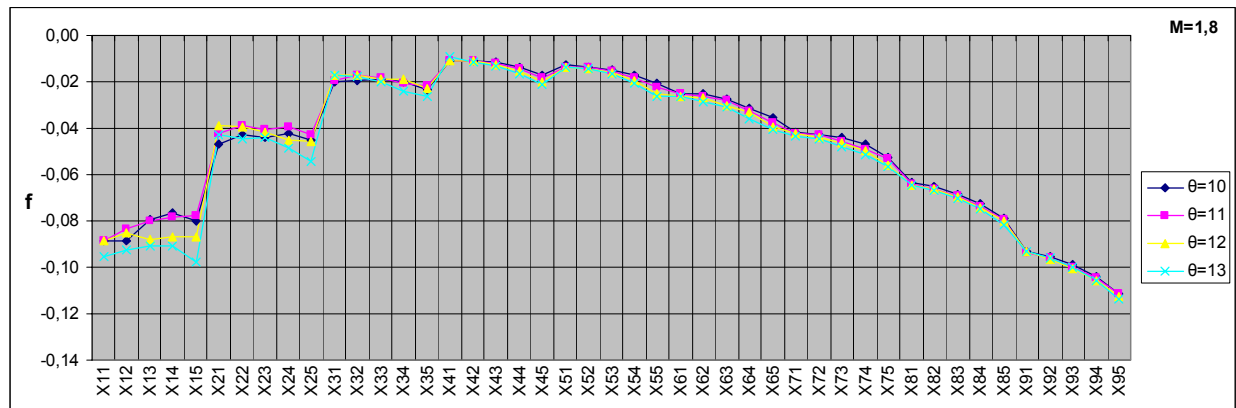

Dijagram 6 - Promena funkcije cilja u funkciji X i $\theta$

Zbirni pregled promenljivih i njima odgovarajućih rezultata proračuna u okolini optimalnog rešenja prikazan je u tabeli 5.

Tabela 5

\begin{tabular}{|c|c|c|c|c|c|c|}
\hline \multirow{2}{*}{ 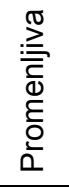 } & \multicolumn{6}{|c|}{$\begin{array}{l}\text { Geometrijski parametri } \\
\text { komandnih površina rakete }\end{array}$} \\
\hline & $b / 2$ & $c t$ & $c r$ & $c t / c r$ & $S$ & $\lambda$ \\
\hline$X_{11}$ & 0,0800 & 0,0280 & 0,0300 & 0,9333 & 0,004640 & 5,517 \\
\hline$X_{12}$ & 0,0800 & 0,0285 & 0,0300 & 0,9500 & 0,004680 & 5,470 \\
\hline$X_{13}$ & 0,0800 & 0,0290 & 0,0300 & 0,9667 & 0,004720 & 5,424 \\
\hline$X_{41}$ & 0,0650 & 0,0280 & 0,0300 & 0,9333 & 0,003770 & 4,483 \\
\hline$X_{42}$ & 0,0650 & 0,0285 & 0,0300 & 0,9500 & 0,003803 & 4,444 \\
\hline$X_{43}$ & 0,0650 & 0,0290 & 0,0300 & 0,9667 & 0,003835 & 4,407 \\
\hline$X_{72}$ & 0,0500 & 0,0285 & 0,0300 & 0,9500 & 0,002925 & 3,419 \\
\hline$X_{73}$ & 0,0500 & 0,0290 & 0,0300 & 0,9667 & 0,002950 & 3,390 \\
\hline$X_{74}$ & 0,0500 & 0,0295 & 0,0300 & 0,9833 & 0,002975 & 3,361 \\
\hline
\end{tabular}

Sličnom varijacijom ograničenja, željenih vrednosti i koeficijenata značajnosti može se zaključiti da se upotrebom izraza za funkciju cilja, u obliku (2), lako dolazi do optimalnog rešenja.

Ukoliko postoji odstupanje maksimuma funkcije cilja od nule, jednostavnom analizom pojedinačnih komponenti funkcije cilja i odgovarajućom korekcijom obezbeđuje se brza konvergencija ka optimalnom rešenju. 
Rezultati proračuna komandnih površina rakete programom WAC:

\begin{tabular}{|c|c|c|c|c|c|c|c|c|c|c|}
\hline \multirow{3}{*}{ 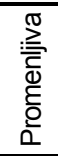 } & \multicolumn{5}{|c|}{$\theta=10$} & \multicolumn{5}{|c|}{$\theta=11$} \\
\hline & \multicolumn{2}{|c|}{$M=0,5$} & \multicolumn{2}{|c|}{$M=1,8$} & \multirow[b]{2}{*}{$\Delta$} & \multicolumn{2}{|c|}{$M=0,5$} & \multicolumn{2}{|c|}{$M=1,8$} & \multirow[b]{2}{*}{$\Delta$} \\
\hline & $C N$ & $x c p / c r$ & $C N$ & $x c p / c r$ & & $C N$ & $x c p / c r$ & $C N$ & $x c p / c r$ & \\
\hline$X_{11}$ & 0,756 & 0,4470 & 0,478 & 0,6863 & 0,2393 & 0,754 & 0,4700 & 0,478 & 0,7100 & 0,2400 \\
\hline$X_{12}$ & 0,751 & 0,4492 & 0,478 & 0,6908 & 0,2416 & 0,749 & 0,4722 & 0,477 & 0,7147 & 0,2425 \\
\hline$X_{13}$ & 0,745 & 0,4514 & 0,476 & 0,6954 & 0,2440 & 0,743 & 0,4745 & 0,476 & 0,7195 & 0,2450 \\
\hline $\mathbf{X}_{41}$ & 0,666 & 0,4048 & 0,459 & 0,6431 & 0,2383 & 0,664 & 0,4234 & 0,459 & 0,6623 & 0,2389 \\
\hline$X_{42}$ & 0,663 & 0,4067 & 0,459 & 0,6474 & 0,2407 & 0,660 & 0,4253 & 0,459 & 0,6667 & 0,2414 \\
\hline$X_{43}$ & 0,659 & 0,4087 & 0,459 & 0,6519 & 0,2432 & 0,657 & 0,4273 & 0,459 & 0,6712 & 0,2439 \\
\hline$X_{72}$ & 0,602 & 0,3620 & 0,455 & 0,6034 & 0,2414 & 0,600 & 0,3761 & 0,455 & 0,6181 & 0,2420 \\
\hline$X_{73}$ & 0,600 & 0,3635 & 0,455 & 0,6076 & 0,2441 & 0,599 & 0,3777 & 0,456 & 0,6223 & 0,2446 \\
\hline$X_{74}$ & 0,598 & 0,3649 & 0,455 & 0,6117 & 0,2468 & 0,597 & 0,3791 & 0,456 & 0,6264 & 0,2473 \\
\hline \multirow{3}{*}{ 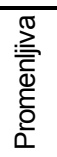 } & \multicolumn{5}{|c|}{$\theta=12$} & \multicolumn{5}{|c|}{$\theta=13$} \\
\hline & \multicolumn{2}{|c|}{$M=0,5$} & \multicolumn{2}{|c|}{$M=1,8$} & & \multicolumn{2}{|c|}{$M=0,5$} & \multicolumn{2}{|c|}{$M=1,8$} & \multirow[b]{2}{*}{$\Delta$} \\
\hline & $C N$ & $x c p / c r$ & $C N$ & $x c p / c r$ & $\Delta$ & $C N$ & $x c p / c r$ & $C N$ & $x c p / c r$ & \\
\hline$X_{11}$ & 0,752 & 0,4936 & 0,478 & 0,7355 & 0,2419 & 0,749 & 0,5174 & 0,479 & 0,7613 & 0,2439 \\
\hline$X_{12}$ & 0,746 & 0,4959 & 0,477 & 0,7404 & 0,2445 & 0,744 & 0,5198 & 0,478 & 0,7662 & 0,2464 \\
\hline $\mathbf{X}_{13}$ & 0,741 & 0,4982 & 0,477 & 0,7452 & 0,2470 & 0,739 & 0,5221 & 0,477 & 0,7711 & 0,2490 \\
\hline $\mathbf{X}_{41}$ & 0,662 & 0,4420 & 0,459 & 0,6816 & 0,2396 & 0,660 & 0,4609 & 0,458 & 0,7010 & 0,2401 \\
\hline$X_{42}$ & 0,658 & 0,4440 & 0,459 & 0,6860 & 0,2420 & 0,656 & 0,4629 & 0,459 & 0,7056 & 0,2427 \\
\hline $\mathbf{X}_{43}$ & 0,655 & 0,4461 & 0,459 & 0,6906 & 0,2445 & 0,653 & 0,4649 & 0,459 & 0,7102 & 0,2453 \\
\hline$X_{72}$ & 0,599 & 0,3904 & 0,456 & 0,6328 & 0,2424 & 0,597 & 0,4047 & 0,456 & 0,6477 & 0,2430 \\
\hline$X_{73}$ & 0,597 & 0,3919 & 0,456 & 0,6371 & 0,2452 & 0,596 & 0,4063 & 0,457 & 0,6519 & 0,2456 \\
\hline$X_{74}$ & 0,595 & 0,3935 & 0,456 & 0,6412 & 0,2477 & 0,594 & 0,4079 & 0,457 & 0,6561 & 0,2482 \\
\hline
\end{tabular}

Na sličan, kao i za komandne površine rakete, izvršen je proračun krila rakete i izbor njihovog optimalnog oblika. Ovako dobijene komandne površine i krila rakete, kao i prethodno usvojeno telo rakete, činili su kompletnu konfiguraciju rakete, koja je bila predmet aerodinamičkog proračuna i validacije rezultata komparativnom metodom, poređenjem proračunom dobijenih rezultata sa eksperimentalnim podacima, dobijenim ispitivanjem modela rakete $u$ aerotunelu T-38 Vojnotehničkog instituta.

\section{Validacija rezultata}

Radi provere i ocene valjanosti prethodno opisane procedure i izbora optimalnog oblika komandnih površina rakete, primenom programa NLMAC, razvijenog u Vojnotehničkom institutu, i licencnog programa FLUENT, izračunati su aerodinamički koeficijenti kompletne konfiguracije rakete $\mathrm{i}$, na kraju, realizovan eksperiment, kada je odgovarajući model 
rakete [3] izrađen na bazi rezultata aerodinamičkog proračuna. Model je ispitan u trisoničnom aerotunelu T-38 Vojnotehničkog instituta.
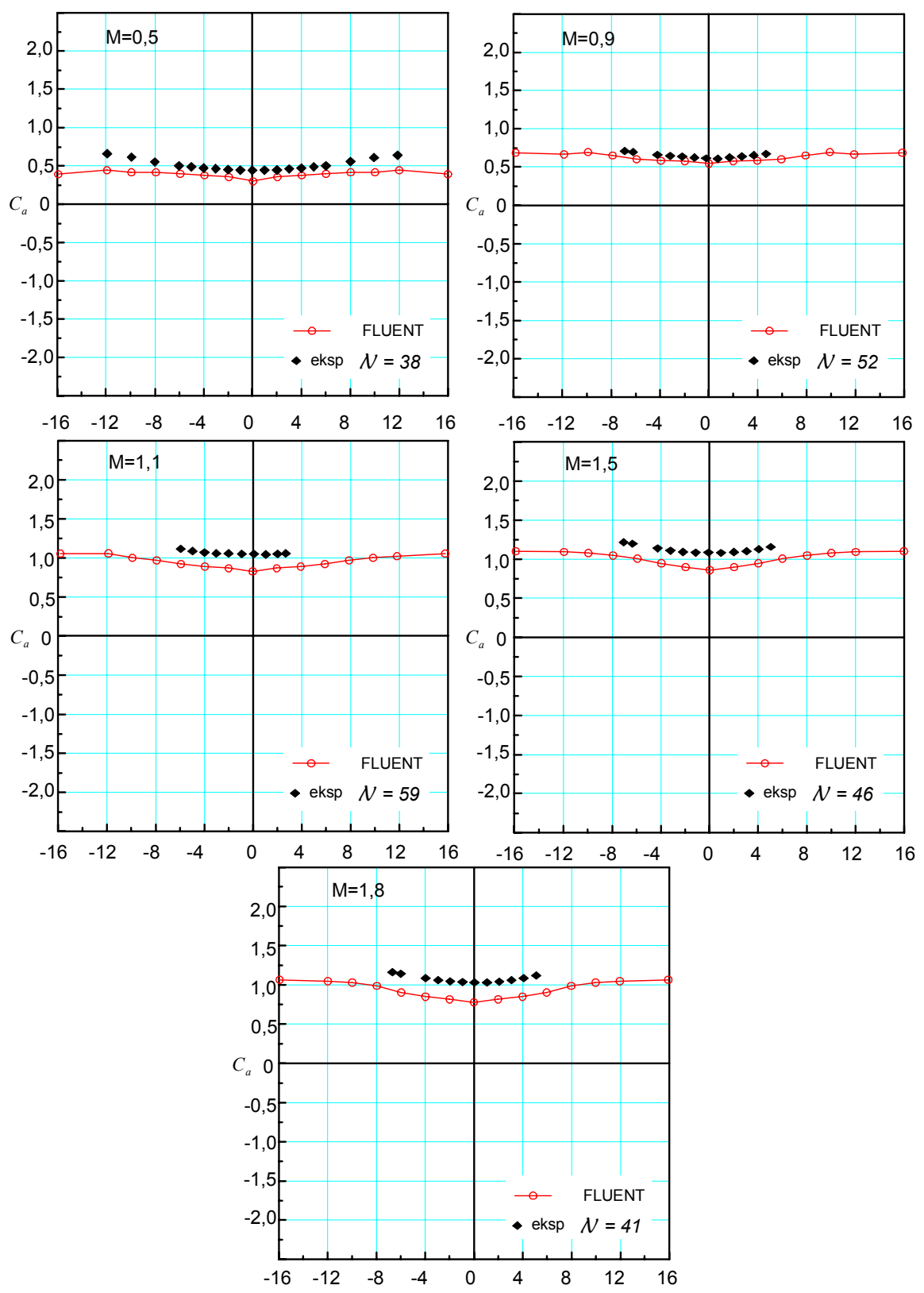

Dijagram 7 - Poređenje rezultata proračuna $\left(\mathrm{C}_{\alpha}\right.$ u funkciji $\alpha$ i M) sa eksperimentalnim podacima 
Uporedni prikaz nekih od rezultata aerodinamičkog proračuna i dobijenih eksperimentalnih rezultata prikazan je na dijagramima 7 i 8 . Podaci se odnose na raketu sa neotklonjenim komandnim površinama.

[4] i [5].

Detaljniji i potpuni rezultati ispitivanja modela rakete mogu se naći u

Oznaka $N$ na dijagramima predstavlja redni broj eksperimenta u aerotunelu.

Dijagram 8 - Poređenje rezultata proračuna $\left(\mathrm{C}_{\mathrm{N}}\right.$ u funkciji $\alpha$ i $\left.\mathrm{M}\right)$ sa eksperimentalnim podacima

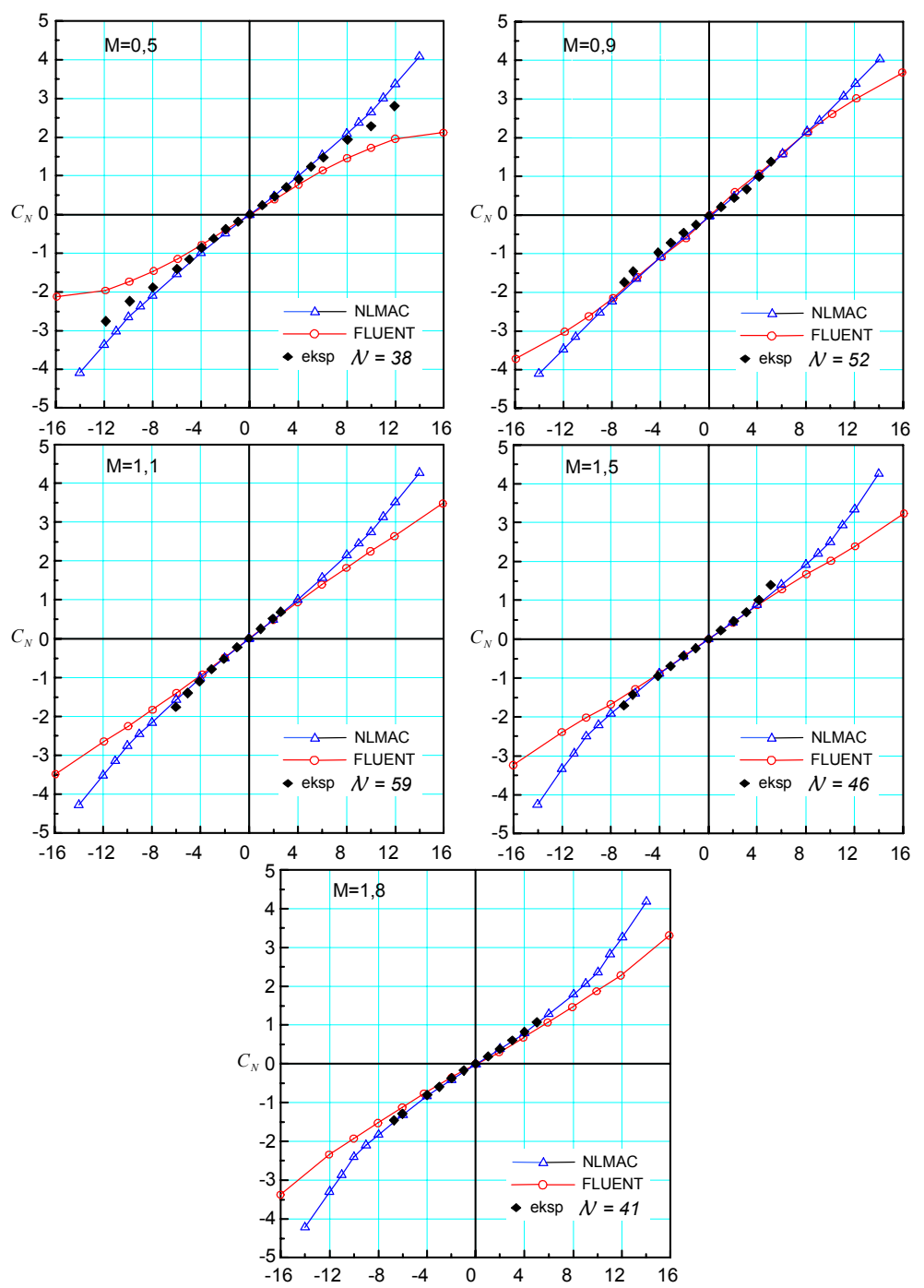


Poređenjem rezultata aerodinamičkog proračuna (izabranog optimalnog rešenja) sa eksperimentalnim podacima dobijenim ispitivanjem modela rakete uočava se međusobna saglasnost, što navodi na zaključak da je opisana procedura preliminarnog aerodinamičkog proračuna prihvatljiva i da može biti primenjivana pri preliminarnim aerodinamičkim projektovanjima sličnih sistema.

Zaključak

Optimizacija procesa preliminarnog aerodinamičkog proračuna raketa je moguća. Na brži i relativno lakši način dolazi se do oblika rakete koji zadovoljava unapred postavljene ciljeve i zadata ograničenja.

Ako je početno definisanje geometrije tela urađeno kvalitetno i ako su funkcije cilja definisane korektno, prethodno optimizovane komandne površine i krila rakete „uklapaju“ se u celu konfiguraciju rakete, tako da proračun kompletne konfiguracije ne zahteva veliki broj iteracija.

Pokazano je da je u aerodinamičkom proračunu korišćeni pristup u definisanju početne geometrije komponenata rakete prihvatljiv i sa aspekta efikasnosti koristan, kao i da je funkcija cilja, definisana na predstavljeni način, efikasna i da umnogome doprinosi optimizaciji procesa preliminarnog aerodinamičkog proračuna rakete, jer omogućava efikasnu analizu odstupanja pojedinih aerodinamičkih i geometrijskih veličina od željenih (ciljnih) vrednosti i time dozvoljava blagovremenu korekciju oblika komponenti rakete.

\section{Literatura}

[1] Nelson A., Nemec M., Aftosmis M.J., Pulliam T.X.: Aerodynamic Optimization of Rocket Control Surfaces Using Cartesian Methods and CAD Geometry, $23^{\text {rd }}$ AIAA Applied Aerodynamics Conference, Toronto, 2005.

[2] Carpentieri G., Van Tooren M.J.L., Koren B.: Aerodynamic Shape Optimization by Means of Sequential Linear Programming Techniques, Europian Conference on CFD, Netherlands, 2006.

[3] V3-2892-P-025, Vojnotehnički institut, Beograd, 2006.

[4] VTI-2936-A-025, Vojnotehnički institut, Beograd, 2006.

[5] V3-2965-I-025, Vojnotehnički institut, 2007. 